\title{
Modeling the effects of land-use optimization on the soil organic carbon sequestration potential
}

\author{
YAO Jingtao ${ }^{1,2},{ }^{*}$ KONG Xiangbin ${ }^{1,2}$ \\ 1. College of Land Science and Technology, China Agricultural University, Beijing 100193, China; \\ 2. Key Laboratory for Agricultural Land Quality, Monitoring and Control, The Ministry of Land and Resources, \\ Beijing 100193, China
}

\begin{abstract}
Increasing soil organic carbon (SOC) sequestration is not only an efficient method to address climate change problems but also a useful way to improve land productivity. It has been reported by many studies that land-use changes can significantly influence the sequestration of SOC. However, the SOC sequestration potential (SOCP, the difference between the saturation and the existing content of SOC) caused by land-use change, and the effects of land-use optimization on the SOCP are still not well understood. In this research, we modeled the effects of land-use optimization on SOCP in Beijing. We simulated three land-use optimization scenarios (uncontrolled scenario, scale control scenario, and spatial restriction scenario) and assessed their effects on SOCP. The total SOCP $(0-20 \mathrm{~cm})$ in Beijing in 2010 was estimated as $23.82 \mathrm{Tg} \mathrm{C}$ or $18.27 \mathrm{t} \mathrm{C/ha}$. In the uncontrolled scenario, the built-up land area of Beijing would increase by $951 \mathrm{~km}^{2}$ from 2010 to 2030, and the SOCP would decrease by $1.73 \mathrm{Tg} \mathrm{C}$. In the scale control scenario, the built-up land area would decrease by $25 \mathrm{~km}^{2}$ and the SOCP would increase by $0.07 \mathrm{Tg} C$ from 2010 to 2030 . Compared to the uncontrolled scenario, the SOCP in 2030 of Beijing would increase by $0.77 \mathrm{Tg} \mathrm{C}$ or $0.64 \mathrm{t} \mathrm{C} / \mathrm{ha}$ in the spatial restriction scenario. This research provides evidence to guide planning authorities in conducting land-use optimization strategies and estimating their effects on the carbon sequestration function of land-use systems.
\end{abstract}

Keywords: soil organic carbon saturation; carbon sequestration potential; land-use change; modeling; Beijing

\section{Introduction}

The soil organic carbon (SOC) pool is the largest carbon pool in the global terrestrial ecosystem (about $1550 \mathrm{Gt}$ ) (Lal, 2004). The SOC level represents a dynamic carbon equilibrium of input from photosynthetic carbon and output through organic matter erosion, soil respiration, and leaching (Chapin III et al., 2011). SOC sequestration refers to the transfer of $\mathrm{CO}_{2}$ in the atmospheric system into the SOC pool for safe storage (Lal, 2004). SOC sequestration

\footnotetext{
Received: 2017-05-09 Accepted: 2017-09-15

Foundation: Key Research Program of Beijing Natural Science Foundation, No.8151001

Author: Yao Jingtao (1990-), PhD, specialized in the modeling and optimization of land-use changes and GIS. E-mail: jingtao_yao@cau.edu.cn

"Corresponding author: Kong Xiangbin (1969-), Professor, specialized in land use and land cover change. E-mail:kxb@cau.edu.cn
} 
is not only an important process in global carbon cycling, but also a key process in improving the quality of soils (West and Post, 2002; Armstrong et al., 2003; Lal, 2004; Pan et al., 2004; Blair et al., 2006). However, the carbon holding capacity of soil is limited by both the carbon input and the stabilization mechanisms of soil organic matter (Six et al., 2002). The concept of soil carbon saturation has been proposed, analyzed, and estimated in many studies (Stewart et al., 2008; Du et al., 2014). On the basis of the observation of long-term field experiments in Africa, Asia, Australia, Europe, and America (Grant et al., 2001; Bayer et al., 2006; Kamoni et al., 2007; Yang et al., 2007; Young et al., 2009; Angers et al., 2011), it has also been proved that the saturation of SOC does occur. The SOC content will show little or no significant changes when the existing SOC level achieves saturation. The saturation of SOC is correlated with temperature, water input (precipitation and irrigation), and soil properties (Chung et al., 2008; Stewart et al., 2008).

With the understanding of soil carbon saturation, SOC sequestration potential (SOCP) was used to evaluate the carbon sequestration function of land-use systems (Qin et al., 2013). SOCP refers to the soil carbon saturation deficit, i.e. the difference between the saturation and existing SOC level (Qin et al., 2013). Several process-level models, such as CENTURY (Ardö and Olsson, 2003; Lugato et al., 2014) and DNDC (Zhang et al., 2015), have been developed to estimate the SOCP. However, the limitation of the process-level model is that the site-specific parameters are usually not available in practice. Another commonly adopted method to estimate the SOCP is to upscale the SOCP from the specific site scale to the large area scale (Lal, 2002; Lu et al., 2009). This method ignores the heterogeneity of climate and soil conditions, which will determine the SOCP to some degree. In order to develop a practical approach to evaluate the SOC sequestration function of land-use systems, a statistical model was proposed to estimate the saturation level of SOC (Qin and Huang, 2010). The model was developed with the information from field experiments, and it has been widely adopted to estimate the SOCP of land-use systems (Qin et al., 2013). In previous studies, it was presumed that the structure and spatial distribution of land-use types would not change in the short or long term (Qin et al., 2013). This assumption is flawed since land-use systems continuously change in the real world (Foley et al., 2005; Wright and Wimberly, 2013). Particularly in China, the land-use system is experiencing dramatic changes under the force of urbanization and population growth (Liu et al., 2003). Soil sealing as a consequence of urbanization will decrease the SOCP (Munafò et al., 2013). Soil reconstruction as a consequence of reclamation and afforestation will increase the SOCP (Ussiri and Lal, 2005). The SOCP is highly determined by land-use changes (Wang et al., 2016; Yang et al., 2017). Optimization of land-use change would contribute to improving the carbon sequestration function of land-use systems.

Land-use change research has a long history and many simulation models have been developed (Veldkamp and Lambin, 2001; Han et al., 2005). The Markov chain (Al-sharif and Pradhan, 2014; Mondal et al., 2014) and the CLUE-S model (Verburg et al., 2002; Jiang et al., 2015) are very popular models. The Markov chain model was developed based on the historical knowledge of land-use changes. In this model, the transition probabilities between land-use types are assumed stable across time. The model has been applied to simulate land-use changes under the natural evolution process of land-use systems. The CLUE-S model was developed based on the driving factors of land-use, and combines the structural 
and spatial allocation changes of land-use types. The model is applied to simulate both the structure and the spatial distribution change of land-use types. However, the conversion setting of land-use types is partly empirical-based. This setting will increase uncertainties of simulation results and influence the application of the model. Since the empirical-based setting in CLUE-S is highly related to the historical knowledge of land-use changes, developing a land-use change model coupling the CLUE-S concept and the historical knowledge of land-use changes would contribute to the application and performance of land-use change simulation. The major challenge in developing this model is to estimate the transition probability matrix based on the historical matrix and land-use optimization strategies, i.e. the scale control planning (the maximum of built-up land, the minimum of arable land, etc.).

Land-use changes which affect the carbon sequestration function of land-use systems, are highly related to land-use optimization policies. It is necessary to model the effects of land-use changes on SOCP. This research will provide evidence to policy-makers and thus improve the SOC sequestration function of land-use systems. In the following sections of this article, we first describe the study area and data materials. Second, we introduce the land-use change simulation model and the SOCP estimating methods. Third, we validate the land-use change simulation method, make a multi-scenario simulation of land-use optimization, and estimate the effects of land-use optimization on SOCP. Last, we propose the land-use optimization policies.

\section{Study area and data materials}

\subsection{Study area}

Beijing, located in the north of the Northern China Plain, is the capital of China. It covers an area of approximately $16,800 \mathrm{~km}^{2}$. The geography in this region is characterized by alluvial plain in the south and east, and mountains and hills in the north and west (Wu et al., 2006). The average annual temperature ranges from $9.76^{\circ} \mathrm{C}$ to $13.42^{\circ} \mathrm{C}$, and the average annual precipitation from $424 \mathrm{~mm}$ to $628 \mathrm{~mm}$. In the last two decades, Beijing has experienced rapid population growth and urbanization processes. The population grew from 8.71 million in 1978 to 21.70 million in 2015. Population growth brings huge demand for built-up areas. The built-up land area grew from $1461 \mathrm{~km}^{2}$ in 1990 to $2785 \mathrm{~km}^{2}$ in 2010 . In the process, $1288 \mathrm{~km}^{2}$ of arable land was converted to built-up land. Beijing is a typical region to study land-use changes in urbanization processes (Han et al., 2015). Since the carbon sequestration capability of land-use systems is reduced because of land-use changes in the urbanization processes (Lal, 2004), and population growth leads to the high consumption of non-renewable energy (Zhao et al., 2017), Beijing is under high pressure of the carbon balance and pollution. In order to restrict urban expansion and improve the carbon sequestration function of land-use systems, it is necessary to couple land-use optimization and SOCP in this region.

\subsection{Data materials}

The land-use data of Beijing (1990, 2000, and 2010) was acquired from the Data Center for Resources and Environmental Sciences, Chinese Academy of Sciences (RESDC) (Liu et al., 2002). The data was interpreted from Landsat TM images with a man-machine interactive 
method with an overall accuracy of $81 \%$ (Liu et al., 2002). The format of the database is grid with a spatial resolution of $100 \mathrm{~m} \times 100 \mathrm{~m}$ (Figure 1). The spatial distribution data of the average annual temperature and precipitation from 1990 to 2010 was taken from the records of meteorological stations during this period (http://data.cma.cn/). The Kriging interpolation method was employed to translate the stations' recorded data to spatial distribution maps with a spatial resolution of $100 \mathrm{~m} \times 100 \mathrm{~m}$ (Appendix A). Spatial distribution maps of soil properties, including soil $\mathrm{pH}$, soil clay, soil bulk density and SOC density, came from the China Soil Map (Fischer et al., 2008) (Appendix B). The data was obtained from the Cold and Arid Regions Sciences Data Center at Lanzhou (http://westdc.westgis.ac.cn) (Liu et al., 2006). The data was developed based on the Second National Soil Survey, which was conducted from the late 1970 s to the early 1990 s.

(a) Land-use distribution map in 1990

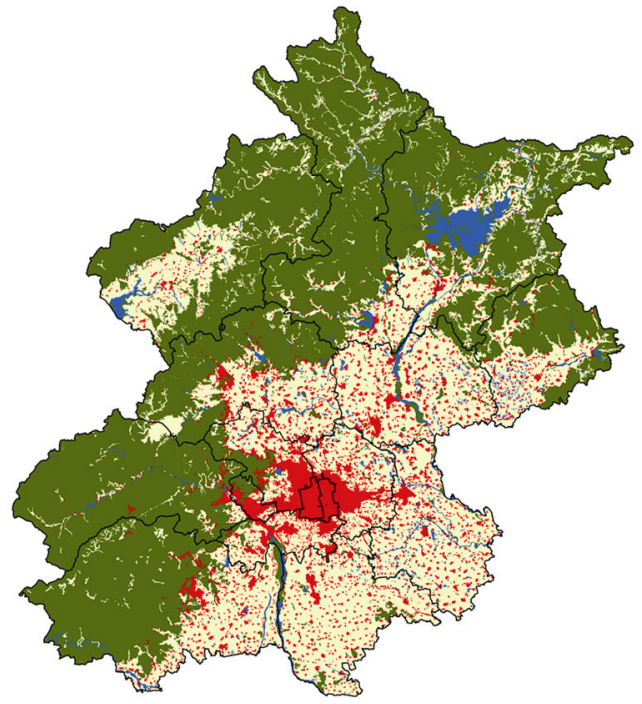

(c) Land-use distribution map in 2010

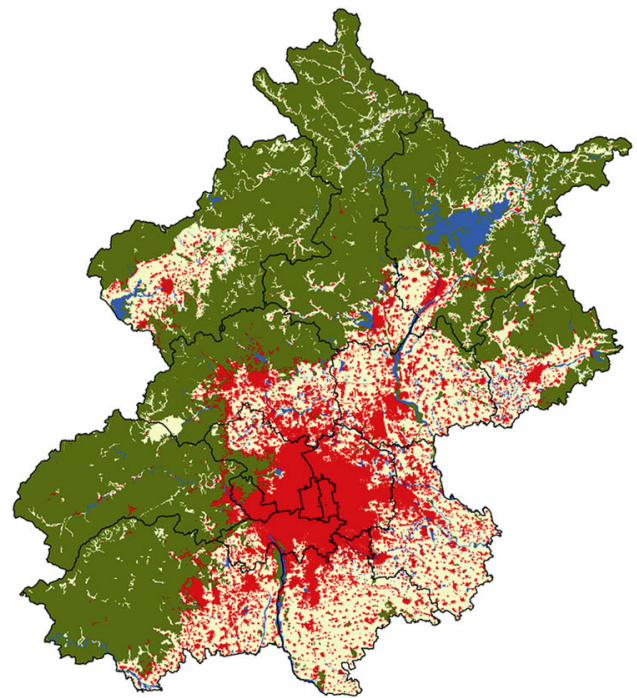

(b) Land-use distribution map in 2000

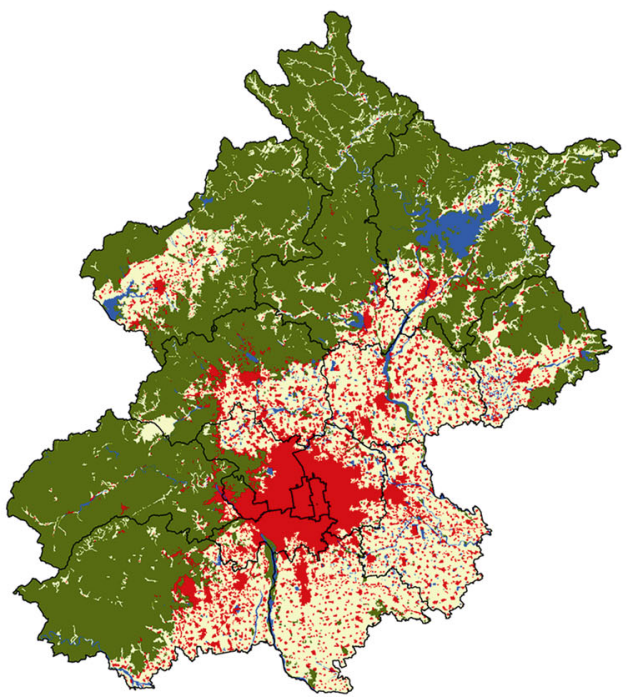

Figure 1 Spatial distribution maps of land-use types in Beijing, 1990-2010 


\section{Methods}

\subsection{Modeling of land-use changes}

\subsubsection{Model framework}

There are two steps in simulating land-use change under different land-use optimization policies. The first step is to simulate the structure changes of land-use types at the regional scale. The second step is to simulate the spatial distribution change at the grid scale (Figure 2). In the first step, both the historical transition probability matrix and the scale control rules are developed to design the future transition matrix. In the second step, the future transition matrix of land-use change is spatially distributed based on the location suitability of land-use types and the spatial restriction rules.

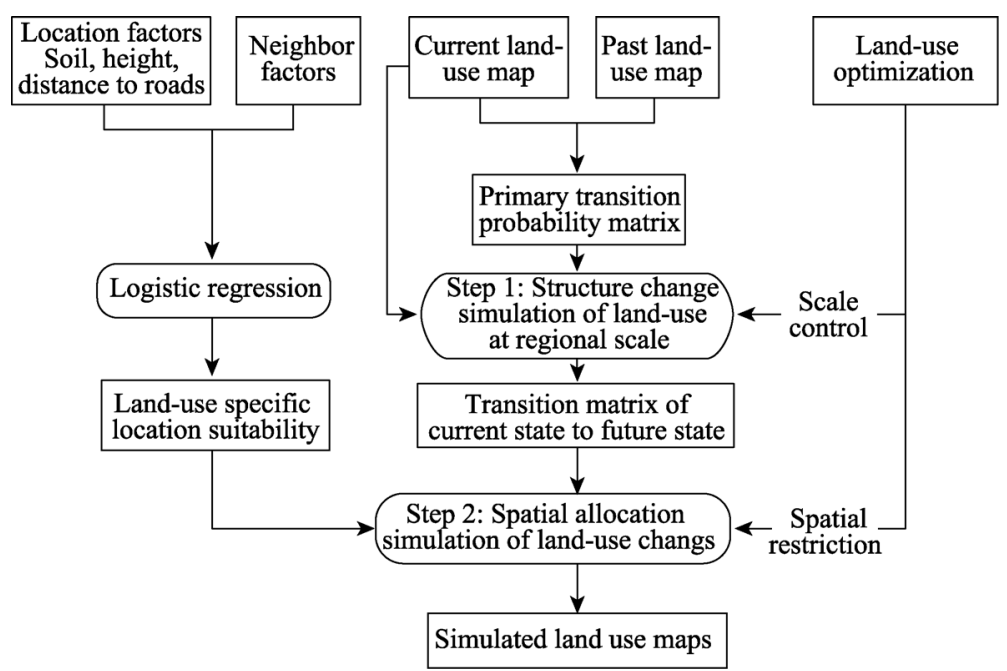

Figure 2 Model framework of land-use change simulation

3.1.2 Structure change simulation of land use at the regional scale

In this model, we assume that the uncontrolled land-use change is submitted to a Markov process (Weng, 2002) and the transition probability matrix is stable in different time states (Alqurashi et al., 2016). The future transition between land-use types can be simulated based on the historical transition probability matrix, which are described in Eqs. 1 and 2.

$$
\begin{aligned}
& p_{h}=\prod_{t=1}^{m-1}\left(\overline{p_{h}} \times \overline{p_{h}}\right) \\
& p_{f}=\prod_{t=1}^{n-1}\left(\overline{p_{h}} \times \overline{p_{h}}\right)
\end{aligned}
$$

where $p_{h}, \overline{p_{h}}$ and $p_{f}$ refer to the historical transition probability matrix, the annual transition probability matrix from past state to current state and the transition probability matrix from current state to future state, respectively. $m$ and $n$ refer to the time step (year) from past state to current state, and current state to future state, respectively.

Since the annual transition probability matrix cannot be directly acquired from the matrix multiplication, a gradient descent approach is employed to obtain the annual transition 
probability matrix (Yao et al., 2016). The transitions between land-use types from the current state to future state and the land-use areas in the future state can be simulated with Eqs.3 and 4.

$$
\begin{gathered}
A_{i j, f}=A_{i, c} \times p_{i j, f} \\
A_{j, f}=\Sigma_{i} A_{i j, f}
\end{gathered}
$$

where $p_{i j, f}$ and $A_{i j, f}$ refer to the transition probability and transition area from land-use $i$ to $j$ from current state to future state, respectively. $A_{i, c}$ and $A_{j, f}$ refer to the area of land-use $i$ in current state and the area of land-use $j$ in future state, respectively.

The scale control policy is a common strategy of land-use optimization. Since the land-use change is a flexible, stable and self-organized process (Verburg et al., 2002), we assumed that the uncontrolled transition matrix reflecting the historical knowledge of land-use changes, would self-adjust to meet the land-use demand of scale control policies with minimum cost (Duan et al., 2006). In this article, the cost is measured by the cross-entropy from the uncontrolled transition matrix to the controlled matrix. The object to derive the controlled matrix with scale control policies is to minimize the value of the cross-entropy cost (Eq.5).

$$
\operatorname{Min} H=\operatorname{Min}\left[\sum_{i=1}^{n} \sum_{j=1}^{n} p_{i j, f} \times \ln \left(\frac{p_{i j, f}}{p_{i j, f}^{*}}\right)\right]
$$

where $p_{i j, f}$ and $p_{i j, f}^{*}$ refer to the transition probabilities from land-use type of $i$ to $j$ in the controlled and uncontrolled matrixes, respectively. $n$ refers to the number of land-use types.

The constraint conditions can be described by Eqs. 6 and 7.

$$
\begin{gathered}
\sum_{j=1}^{n} p_{i j, f}^{*}=1 \\
\sum_{i=1}^{n}\left(p_{i j, f}^{*} \times A_{i, c}\right)=D_{j}
\end{gathered}
$$

where $D_{j}$ represents the scale control value of land-use type $j$.

The constraint optimization problem can be translated into a non-constraint optimization problem with the Lagrangian multiplier method (Bertsekas, 2014), and the translated project function can be described by Eq.8.

$$
\operatorname{Min} H^{*}=\operatorname{Min}\left\{\Sigma_{i} \Sigma_{j} p_{i j, f} \times \ln \left(\frac{p_{i j, f}}{p_{i j, f}^{*}}\right)+\Sigma_{i} \alpha_{i} \times\left(\Sigma_{j} p_{i j, f}^{*}-1\right)+\beta_{j} *\left[\Sigma_{i}\left(p_{i j, f}^{*} * A_{i, c}\right)-D_{j}\right]\right\}
$$

The function can be solved with the first optimal conditions, which can be described by Eqs.9-11.

$$
\begin{gathered}
\frac{\partial H^{*}}{\partial p_{i j, f}^{*}}=-\frac{p_{i j, f}}{p_{i j, f}^{*}}+\alpha_{i}+\beta_{j} \times A_{i, c}=0 \\
\sum_{j} p_{i j, f}^{*}=1 \\
\Sigma_{i}\left(p_{i j, f}^{*} \times A_{i, c}\right)=D_{j}
\end{gathered}
$$

3.1.3 Spatial allocation simulation

On the basis of land transition matrix simulated at the region scale, the spatial allocation 
module is employed to simulate the spatial allocation change at the grid scale. In this module, the land-use specific location suitability of different land-use types and the spatial protection planning strategies were considered to derive the spatial allocation change (Figure 3 ).

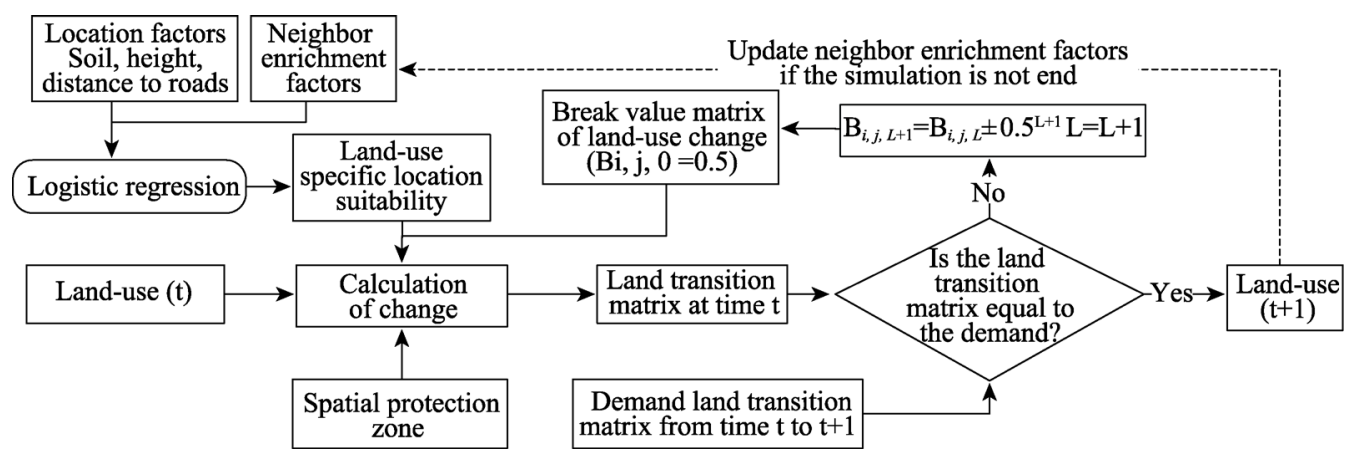

Figure 3 Spatial allocation module of land-use change simulation

The land-use specific location suitability from current land-use type $i$ to the target land-use type $j$ at the specific location loc is determined by the location factors, i.e. soil texture, height, distance, etc., and the neighbor enrichment factors (Verburg et al., 2004) (Eqs.12 and 13).

$$
\begin{gathered}
S_{j,(l o c, i)}=\frac{1}{1+e^{\left(L_{X,(l o c, i)} * W_{L, X, j}+N_{X,(l o c, i)} * W_{N, X, j}+a\right)}} \\
N_{x,(l o c, i)}=\frac{n_{x,(l o c, i)} / n_{(l o c, i)}}{N_{x} / N}
\end{gathered}
$$

where $S_{j,(l o c, i)}$ represents the logistics probability of the specific location loc changing from land-use type $i$ to $j, L_{X,(l o c, i)}$ represents the value vector of local driving factors such as slope, height, distance to main roads, etc., $W_{L, X, j}$ represents the weight vector corresponding to the value vector of local driving factors, $N_{X,(l o c, i)}$ represents the value vector of neighbor enrichment factors, and $W_{N, X, j}$ represents the weight vector of the neighbor enrichment vector. $a$ represents the intercept value of the regression model. $N_{x,(l o c, i)}$ and $n_{x,(l o c, i)}$ represent neighbor enrichment value of land-use type $x$ and the number of grids with land-use type $x$ in the neighborhood of land grid loc with land-use type of $i$, respectively; $n_{(l o c, i)}$ represents the total amount of grids for all land-use types in the neighborhood of the land grid, $N_{x}$ represents the amount of grids of land-use type $x$ in the study area, and $N$ represents the total amount of grids in the study area.

The transition probability from current land-use type $i$ to the target land-use type $j$ at the specific location loc $\left(P_{j,(l o c, i)}\right)$ is determined by both the suitability and the spatial restriction rules (Eq.14).

$$
P_{j,(l o c, i)}=\left[S_{j,(l o c, i)} \times p r t^{|\operatorname{sgn}(i-j)|}\right]^{p r t^{1-|\operatorname{sgn}(i-j)|}}
$$

where prt is equal to 0 when the specific location falls in the spatial protection zone, prt is equal to 1 when the specific location does not fall in the spatial protection zone. sgn refers to the sign function. $|\operatorname{sgn}(i-j)|$ equals 0 when $i$ is equal to $j$, and equals 1 when $i$ is not equal to $j$.

Whether the specific location loc will change from current land-use type $i$ to $j$ is determined by whether the transition probability value at this location is greater than the break 
value (Eq.15). The original break value for all transition probabilities was set as 0.5 . The aggregate number of change areas will be calculated for every iteration and the break value will be modified in the next iteration until the aggregate results of land-use changes at the grid scale meet the demand of transition matrix at the region scale (Eq.15).

$$
B_{i, j, L+1}=B_{i, j, L}+0.5^{L+1} * \frac{\left|\sum_{l o c, i}\left(P_{j,(l o c, i)}>B_{i, j, t}\right)-T_{i, j}+0.0001\right|}{\sum_{l o c, i}\left(P_{j,(l o c, i)}>B_{i, j, t}\right)-T_{i, j}+0.0001}
$$

where $B_{i, j, L}$ represents the break value of land-use transition from $i$ to $j$ at step $L . \Sigma_{l o c, i}$ $\left(P_{j,(l o c, i)}>B_{i, j, t}\right)$ represents the amount of grids of land-use type $i$ and the transition probability to $j$ is greater than the break value. $T_{i, j}$ represents the demand transition number of grid from $i$ to $j$ which is determined by the structure change simulation module at the regional scale.

\subsection{Effects of land-use changes on SOCP}

The urbanization process, featuring land-use change from agricultural land or ecological land to built-up areas, will lead to decrease of SOCP due to soil sealing. On the contrary, reclamation or reforestation will lead to increase of SOCP due to the conversion from built-up land to agricultural or ecological land. In this article, we presumed that the land-use change between agricultural land and ecological land has no effects on SOCP.

The assessment of SOCP first requires the calculation of the saturation and existing level of SOC (Eq.16) (Qin et al., 2013). The existing level of SOC is estimated based on the China Soil Map (Eq.17) (Pan et al., 2004). The saturation level of SOC is estimated based on the statistical model including precipitation, temperature, irrigation, and soil properties (Qin and Huang, 2010) (Eq.18).

$$
\begin{gathered}
S_{P}=\operatorname{SOC}_{S}-S_{P} O C_{E} \\
S O C_{E}=S O C_{C} \times D \times B D \times(1-F) \times 10^{-1} \\
S O C_{S}=140.5 \times e^{-0.021^{*} M T}-98.8 \times e^{-0.42 M W}-39.6 \times e^{-0.1 C L}-4.1 \times p H-27.7
\end{gathered}
$$

where $S O C_{p}$ and $S O C_{S}$ refer to the SOCP and the saturation level of SOC of soil, respectively. $S O C_{E}$ refers to the existing level of SOC (t C/ha) and $S O C_{C}$ refers to the existing SOC concentration $(\mathrm{g} \mathrm{C} / \mathrm{kg}) . D$ refers to the corresponding soil depth $(20 \mathrm{~cm}) . B D$ and $F$ refer to the soil bulk density $\left(\mathrm{g} / \mathrm{cm}^{3}\right)$ and the soil gravel content $(\%)$, respectively. $M T$ and $M W$ refer to the mean annual temperature $\left({ }^{\circ} \mathrm{C}\right)$ and water input (precipitation and irrigation for agricultural land, precipitation for ecological land; unit: $100 \mathrm{~mm}$ ), respectively. $C L$ and $p H$ refer to the soil clay fraction (\%) and soil $\mathrm{pH}$, respectively.

\section{Results}

\subsection{Model validation}

\subsubsection{Quantity validation}

The structure change of land-use systems was simulated based on the transition probability matrix. The probability matrix would remain stable with the historical matrix in the uncontrolled scenario. The uncontrolled matrix could self-adjust to meet the demand of the scale control scenario with minimum cost of cross-entropy. To validate the model, we adopted the transition probability matrix obtained from the historical matrix (1990-2000) and predicted 
the structure of land-use types in 2010 with the uncontrolled scenario and scale-control scenario, where the scale of built-up land would be controlled as the observed value in 2010 . The NRMSE value was employed to evaluate the accuracy of the prediction by comparing the predicted area with the observed area of land-use types in Beijing, 2010 (Table 1).

Table 1 Quantity validation of land-use structure simulated in 2010

\begin{tabular}{|c|c|c|c|c|c|}
\hline \multirow{2}{*}{ Land-use type } & \multirow{2}{*}{$\begin{array}{c}\text { Observed area } \\
\text { (ha) }\end{array}$} & \multicolumn{2}{|c|}{ Uncontrolled scenario } & \multicolumn{2}{|c|}{ Scale control scenario } \\
\hline & & Predicted area (ha) & Error (\%) & Predicted area (ha) & Error $(\%)$ \\
\hline Built-up land & 278464 & 283675 & 1.87 & 278464 & - \\
\hline Agricultural land & 444089 & 420205 & -5.38 & 424308 & -4.45 \\
\hline Ecological land & 918253 & 934608 & 1.78 & 935716 & 1.90 \\
\hline NRMSE & & \multicolumn{2}{|l|}{0.0278} & \multicolumn{2}{|l|}{0.0249} \\
\hline
\end{tabular}

The absolute errors of quantity prediction of land-use types of the uncontrolled and scale-control scenarios range from $1.78 \%$ to $5.38 \%$, and $1.90 \%$ to $4.45 \%$, respectively. The NRMSE value of the scale control scenario is 0.0249 , a little smaller than that in the uncontrolled scenario (0.0278). It can be concluded that the model is satisfied in the two scenarios. Furthermore, the accuracy would be improved with the cross-entropy optimization method when the scale of specific land-use type is controlled.

\subsubsection{Spatial validation}

In this research, the spatial allocation change of land-use types was simulated based on the structure change simulation at the region scale and the land-use specific suitability driven by the location and neighbor factors of land-use cells. To validate the spatial allocation accuracy of the model, we simulated the spatial land-use change from 2000 to 2010 based on the land-use map of 2000 and the transition probability matrix from 2000 to 2010. The kappa statistical approach with multi fuzzy radius (Duan et al., 2004; Pontius et al., 2008) was employed to validate the spatial simulation accuracy of the model.

The kappa coefficient of different land-use types ranges from 0.79 to 0.93 via different fuzzy radius. The aggregate kappa coefficient ranges from 0.87 to 0.91 . Both the specific kappa and the aggregate kappa show a positive correlation with the increase of fuzzy radius (Figure 4). It can be concluded that spatial validation acquired satisfactory results at both the detailed and aggregate levels.

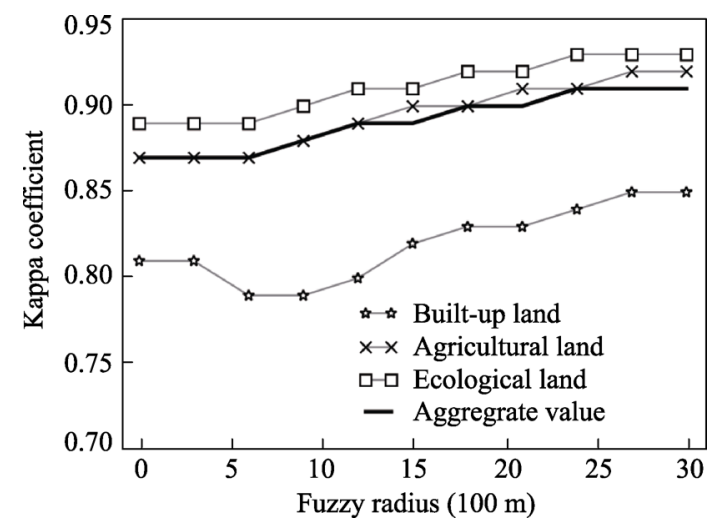

Figure 4 Kappa values of land-use simulation of Beijing, 2010

\subsection{Results of land-use change simulation}

\subsubsection{Scenario setting}

Three scenarios were designed in this research to assess the effects of land-use optimization on the SOCP from 2010 to 2030 in Beijing. The uncontrolled scenario (UCS) was designed as the 
basic scenario to simulate land-use changes following the historical trend of land-use changes. The scale control scenario (SCS) was designed to simulate land-use changes in which the scale of built-up land was controlled to reduce to $2760 \mathrm{~km}^{2}$ in 2030 based on the overall urban plan of Beijing (http://www.china.org.cn/china/2017-03/30/content_40527731.htm). The spatial restriction scenario (SRS) was designed to simulate land-use changes in which the spatial locations with high SOCP (greater than $20 \mathrm{t} \mathrm{C/ha)} \mathrm{were} \mathrm{set} \mathrm{as} \mathrm{the} \mathrm{protection} \mathrm{zone.}$ Land-use types of grid in the protection zone would not change during the simulation period.

\subsubsection{Simulation results on land-use changes}

In this research, we assumed that the spatial restriction policy would have no effect on the structure change of land-use types at the regional scale. Therefore, the transition probabilities and the structure change of land-use types in the SRS would be the same as that in the UCS. The transition probability from agricultural land to built-up land between 2010 and 2030 would significantly decrease from 0.1822 in the UCS to 0.0680 in the SCS. Meanwhile, the transition probability from ecological land to built-up land would significantly decrease from 0.0163 in the UCS to 0.0035 in the SCS. On the contrary, the transition probability from built-up land to agricultural land and ecological land would increase from 0.0008 in the UCS to 0.0487 in the SCS, and from 0.0013 in the UCS to 0.0801 in the SCS, respectively. It can be concluded that the scale control policy of built-up land would both limit the urbanization process and facilitate the reclamation/reforestation process (Tables 2 and 3). As a consequence, the structure change of land-use types from 2010 to 2030 in the SCS is significantly different from that in the UCS (Figure 5).

Table 2 Transition probabilities of land-use types in the uncontrolled scenario (UCS), 2010-2030

\begin{tabular}{clccc}
\hline & & \multicolumn{3}{c}{ Land-use type 2030 } \\
\cline { 3 - 5 } & & Built-up land & Agricultural land & Ecological land \\
\hline \multirow{2}{*}{ Land-use type 2010 } & Built-up land & 0.9979 & 0.0008 & 0.0013 \\
& Agricultural land & 0.1822 & 0.8106 & 0.0072 \\
& Ecological land & 0.0163 & 0.0019 & 0.9818 \\
\hline
\end{tabular}

Table 3 Transition probabilities of land-use types in the scale control scenario (SCS), 2010-2030

\begin{tabular}{ccccc}
\hline & & \multicolumn{3}{c}{ Land-use type 2030 } \\
\cline { 3 - 5 } & & Built-up land & Agricultural land & Ecological land \\
\hline Land-use type 2010 & Built-up land & 0.8712 & 0.0487 & 0.0801 \\
& Agricultural land & 0.0680 & 0.9238 & 0.0082 \\
& Ecological land & 0.0035 & 0.0019 & 0.9946 \\
\hline
\end{tabular}

Although the scale control policy would restrict the urbanization process and facilitate the reclamation/reforestation process, the central city of the study area would expand both in the UCS or SCS. The major area of the expansion would occur in the southern plain of the region, which is also the major area of agricultural land (Figure 6). The spatial restriction policy would significantly influence the spatial expansion of built-up land, and the spatial expansion of built-up land in the southern plain would be significantly restricted in the SRS. It can be concluded that both the scale control and spatial restriction policies would influence the spatial allocation change of land-use types and this influence is different from different locations and different policies. 
(a) Uncontrolled scenario (UCS)

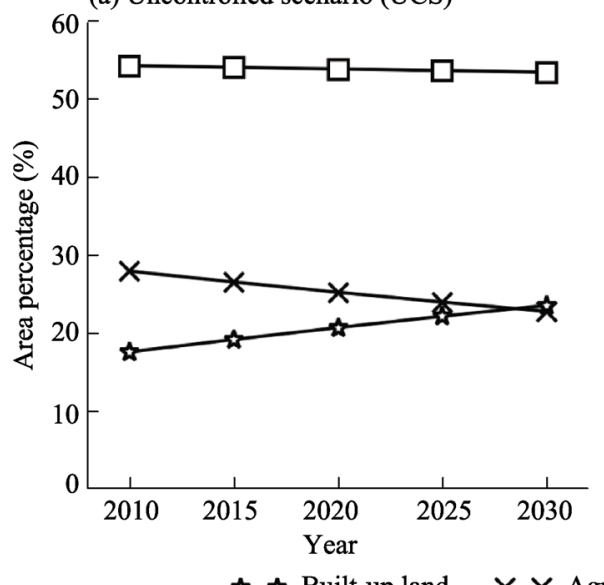

(b) Scale control scenario (SCS)

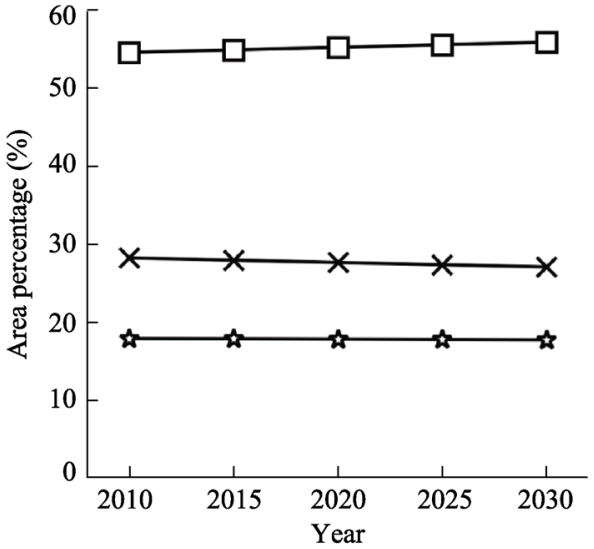

๘ Built-up land $\quad \nprec \times$ Agricultural land $\quad \square-\square$ Ecological land

Figure 5 Land-use structure changes of Beijing in different scenarios

(a) Uncontrolled scenario (UCS), 2020

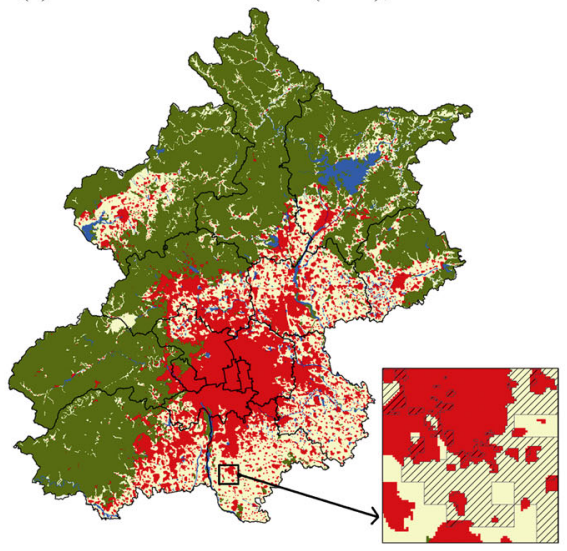

(c) Spatial restriction scenario (SRS), 2020

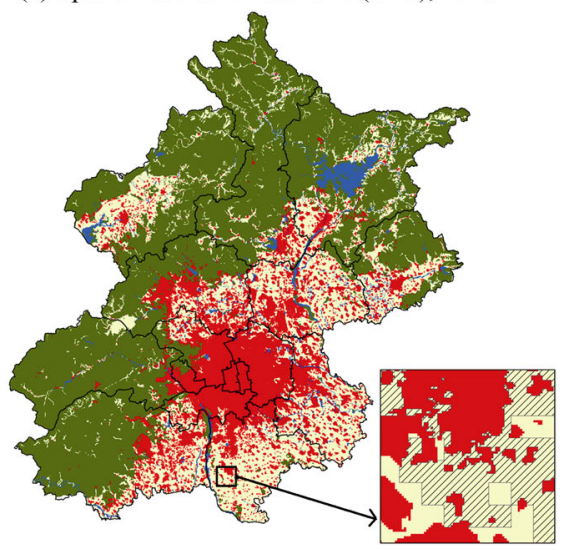

(b) Uncontrolled scenario (UCS), 2030

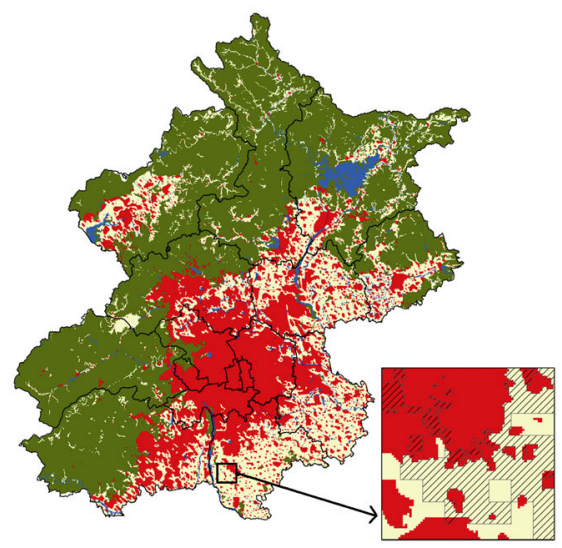

(d) Spatial restriction scenario (SRS), 2030

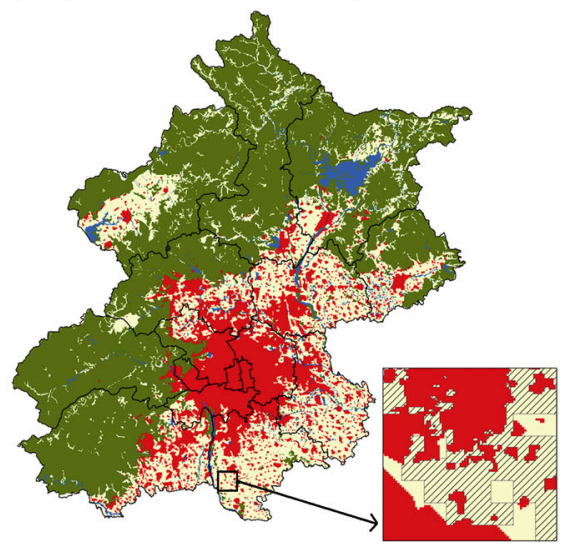


(e) Scale control scenario (SCS), 2020

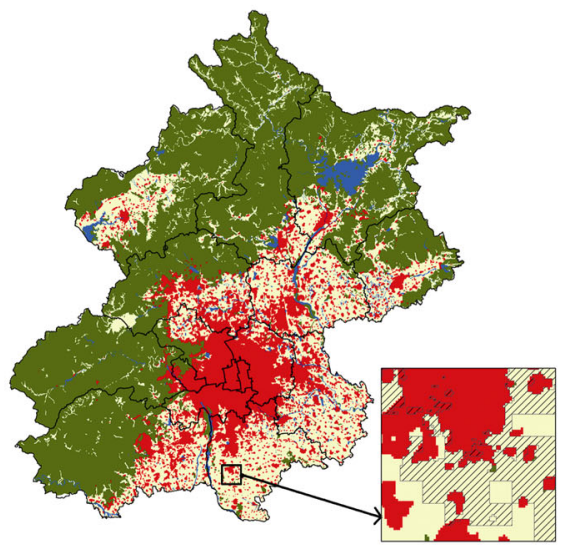

(f) Scale control scenario (SCS), 2030

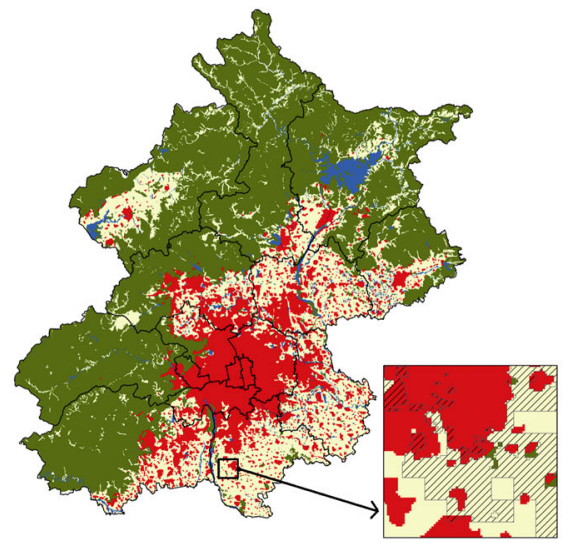

Legend

InA Protection zone $\square$ Built-up land $\quad$ Ecological land

- Water body $\square$ Agricultural land $\square$ County boundary

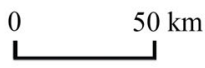

Figure 6 Land-use change simulation results of Beijing under different scenarios

(a) Existing SOC level of Beijing, 2010

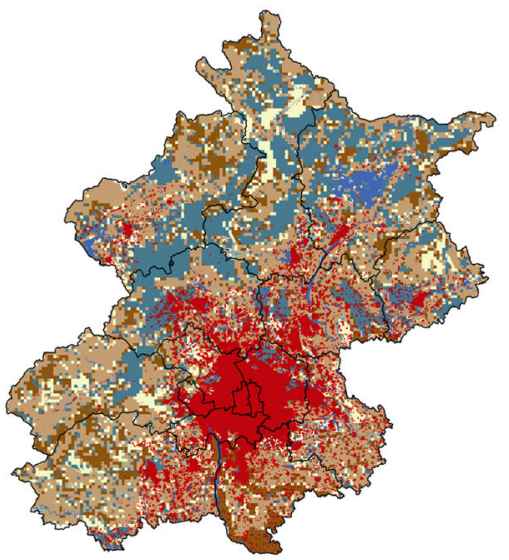

c) SOC sequestration potential of Beijing, 2010

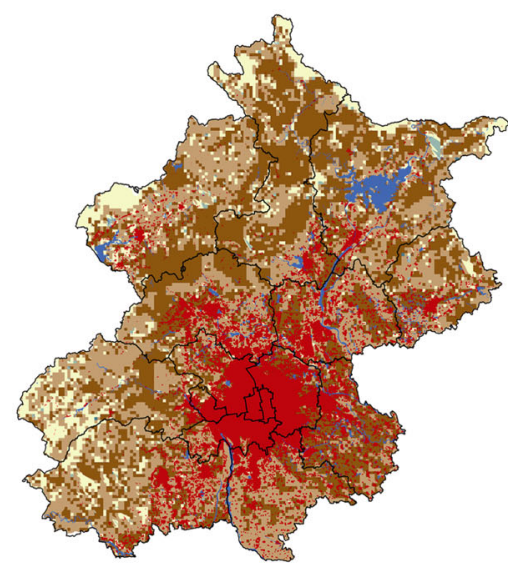

(b) Saturation SOC level of Beijing, 2010

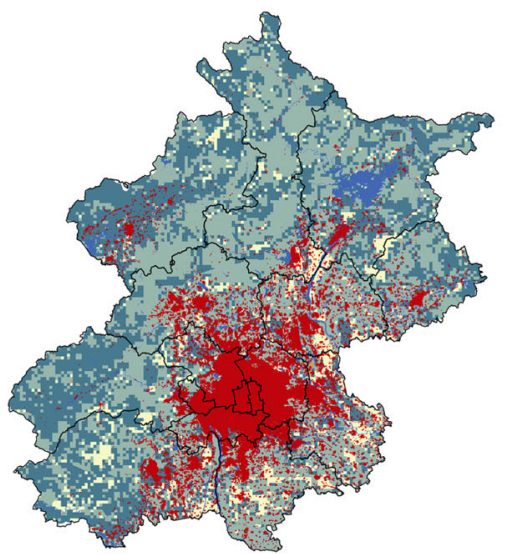

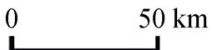

Water body

County boundary

Soil organic carbon (SOC) density ( $\mathrm{t} / \mathrm{ha}$ )

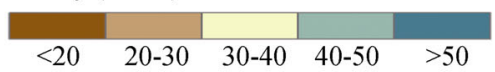

Figure 7 Spatial maps of SOC in Beijing, 2010 


\subsection{Effects of land-use optimization on SOCP}

\subsubsection{SOCP estimated of Beijing in 2010}

Based on the spatial database of soil and land-use maps, we estimated the existing level of SOC, saturation level of SOC and SOCP of the top soil $(0-20 \mathrm{~cm})$ in Beijing in 2010 using the SOCP estimating method (Figure 7).

The existing SOC density in Beijing averaged $30.76 \mathrm{t} \mathrm{C} /$ ha and $33.36 \mathrm{t} \mathrm{C/ha}$ in agricultural land and ecological land, respectively. Based on recommended management practices of agricultural land and natural restoration of ecological land, the saturation level of SOC would reach an average value of $47.60 \mathrm{t} \mathrm{C} / \mathrm{ha}$ and $49.61 \mathrm{t} \mathrm{C} / \mathrm{ha}$ in agricultural land and ecological land, respectively. The SOCP of agricultural land and ecological land can reach 23.82 $\mathrm{Tg} \mathrm{C}$ or averaged $18.27 \mathrm{t} \mathrm{C/ha}$ in Beijing (Figure 8). The major zone of SOCP of agricultural land is found in the southeast and northeast of the region.

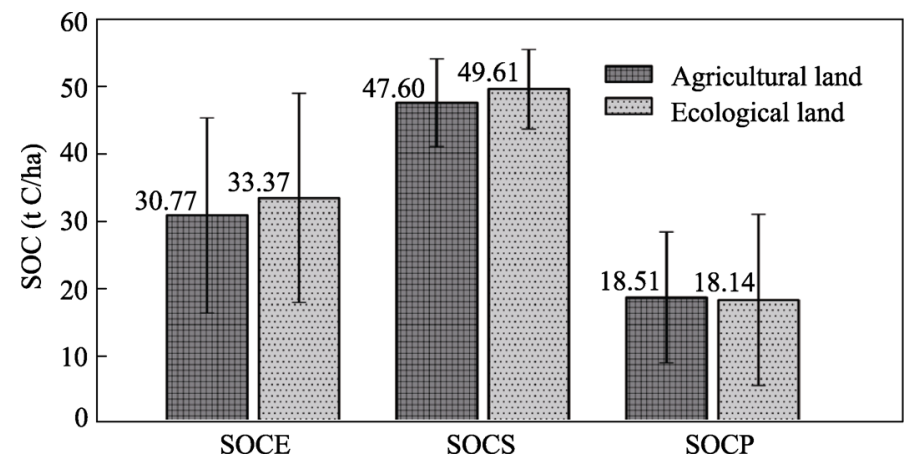

Figure 8 Average SOCP in Beijing, 2010 (SOC, soil organic carbon; SOCE, existing SOC level of the top soil $(0-20 \mathrm{~cm})$; SOCS, saturation SOC level of the top soil; SOCP, SOC sequestration potential of the top soil)

\subsubsection{Effects of land-use optimization on SOCP}

Combining the land-use change simulation results from 2010 to 2030 under the three scenarios (UCS, SCS, SRS) and the SOCP $(0-20 \mathrm{~cm})$ estimating results of Beijing in 2010, the SOCP in the region would decrease $1.73 \mathrm{Tg} \mathrm{C}$ in the UCS (from 23.82 to $22.09 \mathrm{Tg} \mathrm{C}$ ), 0.95 $\mathrm{Tg} \mathrm{C}$ in the SRS, and increase $0.06 \mathrm{Tg} \mathrm{C}$ in the SCS between 2010 and 2030 because of land-use changes. The average SOCP would increase from $18.27 \mathrm{t} \mathrm{C/ha}$ to $18.91 \mathrm{t} \mathrm{C} / \mathrm{ha}$ in the SRS (Figure 9). The average SOCP in agricultural land would increase from $18.51 \mathrm{t} \mathrm{C} / \mathrm{ha}$ to $20.26 \mathrm{t} \mathrm{C} /$ ha in the SRS. The average SOCP in ecological land would increase from 18.14 t C/ha to $18.34 \mathrm{t} \mathrm{C} /$ ha in the SRS (Figures 8 and 10). It can be concluded that both the scale control and spatial restriction policies would have positive effects on the SOCP of land-use systems.

\section{Discussion}

In this research, we developed a land-use change simulation model to simulate the structure and spatial allocation changes of land use under different optimization scenarios. The model is genetic since it is developed on the basis of the historical knowledge of land-use changes, and it is also flexible since it can be easily adapted to the scale control or spatial restriction policies. The spatial allocation simulation module in the model was developed based on 
(a) Uncontrolled scenario (UCS)

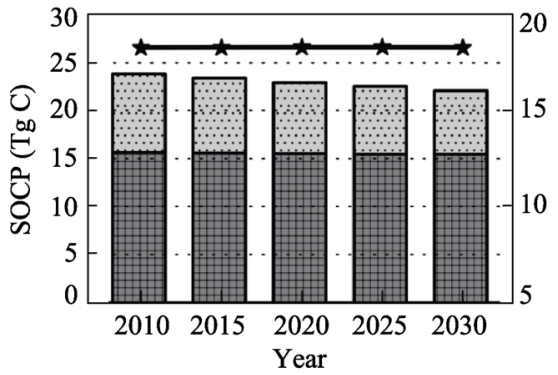

(c) Scale control scenario (SCS)

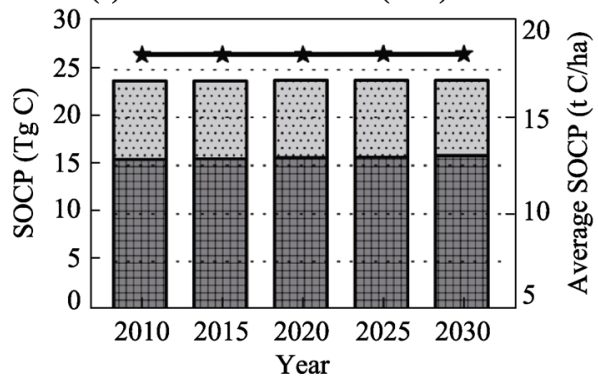

(b) Spatial restriction scenario (SRS)

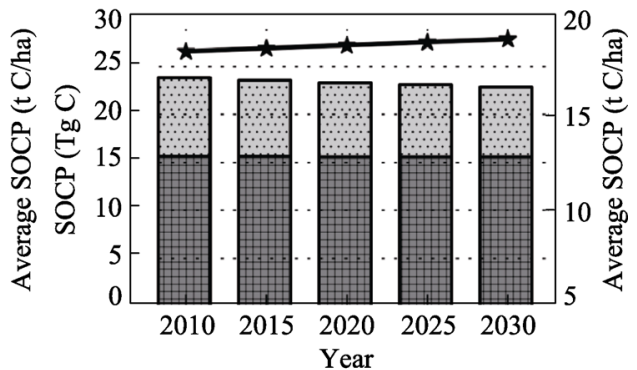

Figure 9 Effects of land-use changes on SOCP from 2010 to 2030 in different scenarios (SOCP, soil organic carbon sequestration potential of top soil of $0-20 \mathrm{~cm}$ )

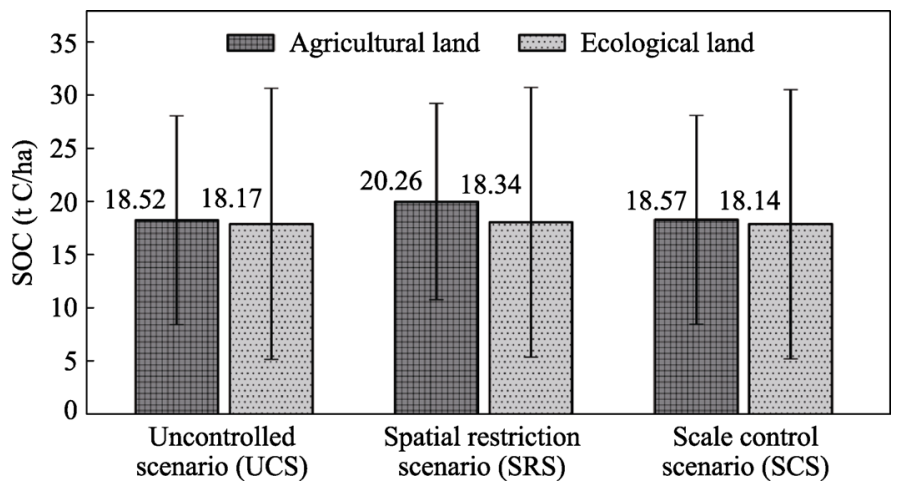

Figure 10 Average SOCP of Beijing in 2030 in different scenarios (SOCP, soil organic carbon sequestration potential of top soil of $0-20 \mathrm{~cm}$ )

the historical transition probability matrix instead of the land-use type specific settings, as in the CLUE-S model. Since the specific settings of conversion elasticity of land-use types in the CLUE-S model are often empirically based, the model developed in this research can improve the uncertainties of land-use change simulation.

The saturation level of SOC of agricultural and ecological land was estimated by a statistical model driven by temperature, irrigation, precipitation, soil clay, and soil $\mathrm{pH}$. This model was developed based on the information from 95 global long-term agricultural experiments (Qin and Huang, 2010). The model was validated against independent data from 19 long-term agricultural experiments in China, and results suggest that the model performs well (Qin and Huang, 2010). The model has been widely adopted to estimate the saturation level of SOC in agricultural systems (Qin and Huang, 2010; Luo et al., 2011; Qin et al., 2013). Since the model was developed and validated based on the information of agricultural 
systems, it would increase the uncertainty of this research using the model to estimate the saturation level of SOC of ecological land. However, the major land-use change in Beijing is the conversion between agricultural land and built-up land (He et al., 2001; Wu et al., 2006). The area and allocation of ecological land are relatively stable in historical and future land-use changes. In consequence, the uncertainty of the SOC saturation estimation of the ecological land has little effect on the research result.

Recent studies show that built-up land can also sequester carbon in soil through the application of residuals to pervious surfaces (Lorenz and Lal, 2009; Brown et al., 2012). However, whether the soil could sequester $\mathrm{C}$ in the built-up land is correlated with both the scale and management practices of pervious surfaces, and few studies have been conducted to reveal the SOC sequestration of built-up land in China. In this article, the SOC sequestration in built-up land is neglected and we assume that the SOC level would not change in the built-up land. Similar assumptions can also be found in other studies (Grimm et al., 2008).

Despite the uncertainty of both land-use change simulation and SOCP estimation, this article provides a new way to estimate the effects of land-use optimization on the carbon sequestration function of land-use systems by coupling the land-use change simulation model and knowledge of SOC saturation. This coupling is new and essential since it can provide evidence for planning authorities to understand the relations between land-use optimization policies and the carbon sequestration function of land-use systems. It is also expected that the coupling model will be improved according to the development of land-use change simulation methods, the theoretical improvement of soil carbon saturation, and the long-term experimental data accumulation in different land-use systems.

The methods and results presented in this research are universal and representative and they are applicable to other regions. First, the land-use change simulation model developed in this article is applicable to simulate and analyze land-use changes with land-use optimization scenarios in other regions. Second, the coupling of land-use change simulation and the carbon sequestration function of land-use systems should also be applied to other regions where landscape is dramatically changing as a consequence of urbanization. It is necessary to discuss the effects of land-use changes on the carbon sequestration function of land-use systems in these regions and to evaluate the effects of land-use optimization policies on the basis of this coupling analysis.

\section{Conclusions}

In order to estimate the effects of land-use optimization on SOCP and improve the SOC sequestration function of land-use systems through land-use optimization policies, a coupling analysis was conducted by combining a land-use change simulation model and the SOCP $(0-20 \mathrm{~cm})$ estimating method in this research. The effects of land-use changes on SOCP were estimated based on SOC saturation knowledge. Three land-use optimization scenarios were designed and studied in this research to discuss the effects of land-use optimization on land-use changes and SOCP from 2010 to 2030 in Beijing. The results demonstrated that land-use changes significantly influence the SOCP, and that both the scale control of built-up land and the spatial restriction setting of high SOCP areas can have a positive effect on the carbon sequestration function of land-use systems in Beijing.

Some specific measures can be adopted to improve the carbon sequestration function of 
land-use systems. First, controlling the scale of built-up land should consider not only population growth but also the balance of carbon sequestration. Second, areas of high SOCP should be recognized and protected based on the carbon saturation knowledge. These areas are important carbon pools, and can constitute a restriction line to shape the expansion of built-up land.

\section{Acknowledgments}

We wish to thank the timely help given by Dr. Song Wei in improving the writing of this article. The land-use change simulation model was developed with Python language and was registered in the Copyright Protection Center of China (registration No. 2017SRBJ0017). The model is open source. Anyone is free to use the model under the MIT license from https:/github.com/YaoJT/LCMS.

\section{References}

Alqurashi A F, Kumar L, Sinha P, 2016. Urban land cover change modelling using time-series satellite images: A case study of urban growth in five cities of Saudi Arabia. Remote Sensing, 8(10): 838.

Al-sharif A A, Pradhan B, 2014. Monitoring and predicting land use change in Tripoli Metropolitan City using an integrated Markov chain and cellular automata models in GIS. Arabian Journal of Geosciences, 7(10): 4291-4301.

Angers D A, Arrouays D, Saby N P A et al., 2011. Estimating and mapping the carbon saturation deficit of French agricultural topsoils. Soil Use and Management, 27(4): 448-452.

Ardö J, Olsson L, 2003. Assessment of soil organic carbon in semi-arid Sudan using GIS and the CENTURY model. Journal of Arid Environments, 54(4): 633-651.

Armstrong R D, Millar G, Halpin N V et al., 2003. Using zero tillage, fertilisers and legume rotations to maintain productivity and soil fertility in opportunity cropping systems on a shallow vertosol. Australian Journal of Experimental Agriculture, 43(2): 141-153.

Bayer C, Lovato T, Dieckow J et al., 2006. A method for estimating coefficients of soil organic matter dynamics based on long-term experiments. Soil and Tillage Research, 91(1/2): 217-226.

Bertsekas D P, 2014. Constrained Optimization and Lagrange Multiplier Methods. Academic Press.

Blair N, Faulkner R D, Till A R et al., 2006. Long-term management impacts on soil C, N and physical fertility: Part I: Broadbalk experiment. Soil and Tillage Research, 91(1/2): 30-38.

Brown S, Miltner E, Cogger C, 2012. Carbon sequestration potential in urban soils. In: Carbon Sequestration in Urban Ecosystems. Springer: 173-196.

Chapin III F S, Matson P A, Vitousek P, 2011. Principles of terrestrial ecosystem ecology. Springer Science \& Business Media.

Chung H, Grove J H, Six J, 2008. Indications for soil carbon saturation in a temperate agroecosystem. Soil Science Society of America Journal, 72(4): 1132-1139.

Du Z L, Wu W L, Wu Q Z et al., 2014. Long-term manure amendments enhance soil aggregation and carbon saturation of stable pools in North China Plain. Journal of Integrative Agriculture, 13(10): 2276-2285.

Duan Z Q, Verburg P H, Zhang F R et al., 2004. Construction of a land-use change simulation model and its application in Haidian District, Beijing. Acta Geographica Sinica, 59(6): 1037-1047. (in Chinese)

Duan Z Q, Zhang F R, Miao L M, 2006. Land use scenario analysis based on the IPAT-S script language method and its application. Transactions of the Chinese Society of Agricultural Engineering, 22(7): 75-81.

Fischer G, Nachtergaele F, Prieler S et al., 2008. Global agro-ecological zones assessment for agriculture (GAEZ 2008). IIASA, Laxenburg, Austria and FAO, Rome, Italy.

Foley J A, DeFries R, Asner G P et al., 2005. Global consequences of land use. Science, 309(5734): 570-574. 
Grant R F, Juma N G, Robertson J A et al., 2001. Long-term changes in soil carbon under different fertilizer, manure, and rotation. Soil Science Society of America Journal, 65(1): 205-214.

Grimm N B, Faeth S H, Golubiewski N E et al., 2008. Global change and the ecology of cities. Science, 319(5864): 756-760.

Han B, Wang X, Ouyang Z, 2005. Saturation levels and carbon sequestration potentials of soil carbon pools in farmland ecosystems of China. Rural Eco-environment, 21(4): 6-11.

Han H, Yang C, Song J, 2015. Scenario simulation and the prediction of land use and land cover change in Beijing, China. Sustainability, 7(4): 4260-4279.

He C Y, Shi P J, Chen J et al., 2001. A study on land use/cover change in Beijing area. Geographical Research, 20(6): 680-687. (in Chinese)

Jiang W G, Chen Z, Lei Xuan et al., 2015. Simulating urban land use change by incorporating an autologistic regression model into a CLUE-S model. Journal of Geographical Sciences, 25(7): 836-850.

Kamoni P T, Gicheru P T, Wokabi S M et al., 2007. Evaluation of two soil carbon models using two Kenyan long term experimental datasets. Agriculture, Ecosystems \& Environment, 122(1): 95-104.

Lal R, 2002. Soil carbon sequestration in China through agricultural intensification, and restoration of degraded and desertified ecosystems. Land Degradation \& Development, 13(6): 469-478.

Lal R, 2004. Soil carbon sequestration impacts on global climate change and food security. Science, 304(5677): 1623-1627.

Liu J Y, Liu M L, Deng X Z et al., 2002. The land use and land cover change database and its relative studies in China. Journal of Geographical Sciences, 12(3): 275-282.

Liu J Y, Liu M L, Zhuang D F et al., 2003. Study on spatial pattern of land-use change in China during 1995-2000. Science in China Series D: Earth Sciences, 46(4): 373-384.

Liu Q H, Shi X Z, Weindorf D C et al., 2006. Soil organic carbon storage of paddy soils in China using the 1:1,000,000 soil database and their implications for C sequestration. Global Biogeochemical Cycles, 20(3). doi: 10.1029/2006GB002731.

Lorenz K, Lal R, 2009. Biogeochemical C and N cycles in urban soils. Environment International, 35(1): 1-8.

Lu F, Wang X, Han B et al., 2009. Soil carbon sequestrations by nitrogen fertilizer application, straw return and no-tillage in China's cropland. Global Change Biology, 15(2): 281-305.

Lugato E, Bampa F, Panagos P et al., 2014. Potential carbon sequestration of European arable soils estimated by modelling a comprehensive set of management practices. Global Change Biology, 20(11): 3557-3567.

Luo Z, Wang E, Sun O J et al., 2011. Modeling long-term soil carbon dynamics and sequestration potential in semi-arid agro-ecosystems. Agricultural and Forest Meteorology, 151(12): 1529-1544.

Mondal A, Khare D, Kundu S et al., 2014. Detection of land use change and future prediction with Markov chain model in a part of Narmada River Basin, Madhya Pradesh. Landscape Ecology and Water Management. Springer: $3-14$.

Munafò M, Salvati L, Zitti M, 2013. Estimating soil sealing rate at national level: Italy as a case study. Ecological Indicators, 26: 137-140.

Pan G, Li L, Wu L et al., 2004. Storage and sequestration potential of topsoil organic carbon in China's paddy soils. Global Change Biology, 10(1): 79-92.

Pontius R G, Boersma W, Castella J C et al., 2008. Comparing the input, output, and validation maps for several models of land change. The Annals of Regional Science, 42(1): 11-37.

Qin Z, Huang Y, 2010. Quantification of soil organic carbon sequestration potential in cropland: A model approach. Science China Life Sciences, 53(7): 868-884.

Qin Z, Huang Y, Zhuang Q, 2013. Soil organic carbon sequestration potential of cropland in China. Global Biogeochemical Cycles, 27(3): 711-722.

Six J, Conant R, Paul E A et al., 2002. Stabilization mechanisms of soil organic matter: Implications for C-saturation of soils. Plant and Soil, 241(2): 155-176.

Stewart C E, Paustian K, Conant R T et al., 2008. Soil carbon saturation: Evaluation and corroboration by long-term incubations. Soil Biology and Biochemistry, 40(7): 1741-1750. 
Ussiri D A, Lal R, 2005. Carbon sequestration in reclaimed minesoils. Critical Reviews in Plant Sciences, 24(3): 151-165.

Veldkamp A, Lambin E F, 2001. Predicting land-use change. Agriculture, Ecosystems \& Environment, 85(1-3): $1-6$.

Verburg P H, de Nijs T C, van Eck J R et al., 2004. A method to analyse neighbourhood characteristics of land use patterns. Computers, Environment and Urban Systems, 28(6): 667-690.

Verburg P H, Soepboer W, Veldkamp A et al., 2002. Modeling the spatial dynamics of regional land use: The CLUE-S model. Environmental Management, 30(3): 391-405.

Wang K B, Deng L, Ren Z P et al., 2016. Dynamics of ecosystem carbon stocks during vegetation restoration on the Loess Plateau of China. Journal of Arid Land, 8(2): 207-220.

Weng Q, 2002. Land use change analysis in the Zhujiang Delta of China using satellite remote sensing, GIS and stochastic modelling. Journal of Environmental Management, 64(3): 273-284.

West T O, Post W M, 2002. Soil organic carbon sequestration rates by tillage and crop rotation. Soil Science Society of America Journal, 66(6): 1930-1946.

Wright C K, Wimberly M C, 2013. Recent land use change in the Western Corn Belt threatens grasslands and wetlands. Proceedings of the National Academy of Sciences, 110(10): 4134-4139.

Wu Q, Li H Q, Wang R S et al., 2006. Monitoring and predicting land use change in Beijing using remote sensing and GIS. Landscape and Urban Planning, 78(4): 322-333.

Yang S M, Malhi S S, Li F M et al., 2007. Long-term effects of manure and fertilization on soil organic matter and quality parameters of a calcareous soil in NW China. Journal of Plant Nutrition and Soil Science, 170(2): 234-243.

Yang Y H, Li W H, Zhu C G et al., 2017. Impact of land use/cover changes on carbon storage in a river valley in arid areas of Northwest China. Journal of Arid Land, 9(6): 879-887.

Yao J T, Kong X B, Duan Z Q, 2016. A gradient algorithm for land use transform matrix analysis and land use change simulation. In: Research on the Innovation and Development of Land Resources Sciences in China in a New Era. Xi'an: Northeastern University Press, 456-463. (in Chinese)

Young R R, Wilson B, Harden S et al., 2009. Accumulation of soil carbon under zero tillage cropping and perennial vegetation on the Liverpool Plains, eastern Australia. Soil Research, 47(3): 273-285.

Zhang H X, Sun B, Xie X L et al., 2015. Simulating the effects of chemical and non-chemical fertilization practices on carbon sequestration and nitrogen loss in subtropical paddy soils using the DNDC model. Paddy and Water Environment, 13(4): 495-506.

Zhao G, Guerrero J M, Jiang K et al., 2017. Energy modelling towards low carbon development of Beijing in 2030. Energy, 121: 107-113. 


\section{Appendix A}

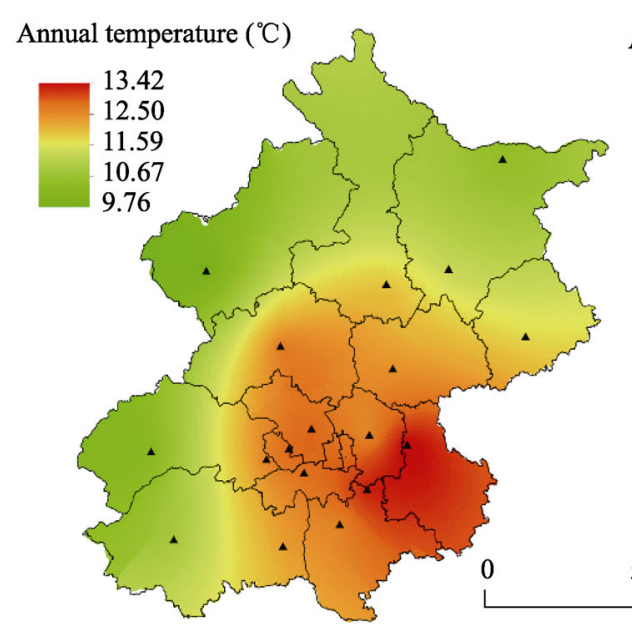

$\triangle$ Meterological station

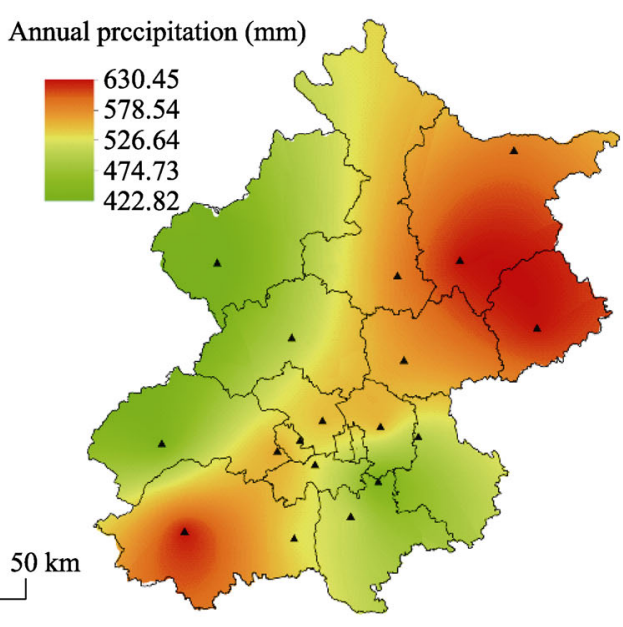

County boundary

(a) Annual temperature of Beijing from 1990 to 2010

(b) Annual precipitation of Beijing from 1990 to 2010

Figure A The average annual temperature and precipitation maps of Beijing from 1990 to 2010 


\section{Appendix B}

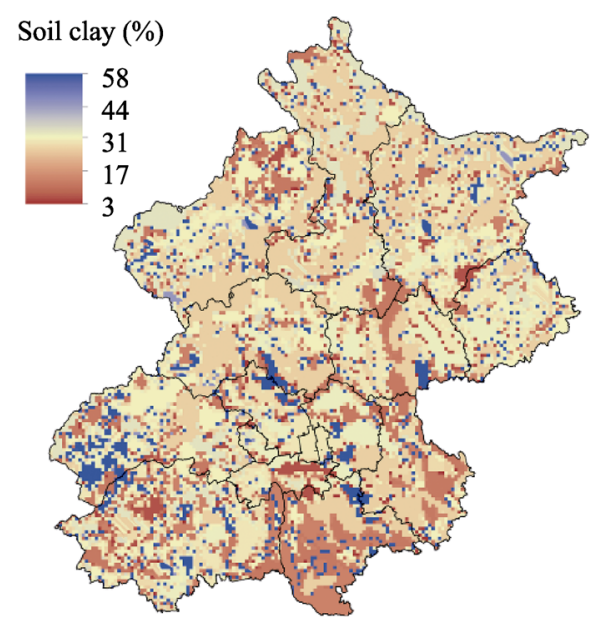

(a) Soil clay of Beijing in 2010

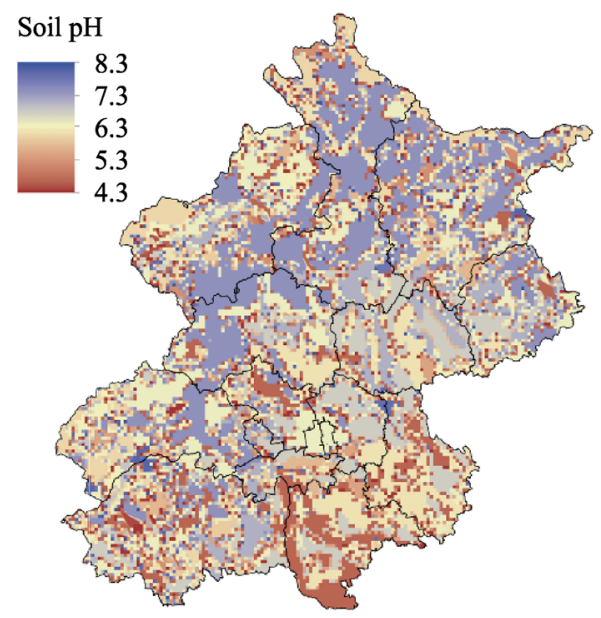

(b) Soil pH of Beijing in 2010

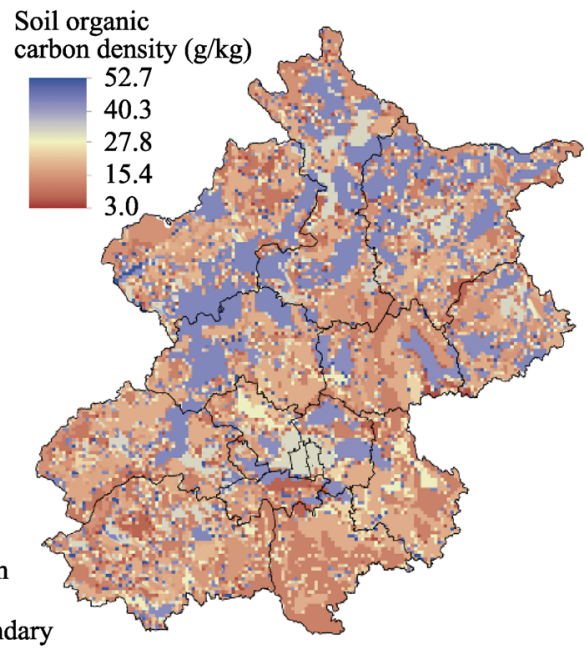

(c) Soil bulk density of Beijing in 2010

(d) Soil organic carbon density of Beijing in 2010

Figure B Spatial distribution maps of soil properties in Beijing, 2010

Note: The data was developed based on the Second National Soil Survey, which was conducted from the late 1970 s to the early 1990 s. 